\title{
Histopathological and nephroprotective study of aqueous stem bark extract of Ficus racemosa in drug induced nephrotoxic rats.
}

\author{
Shivalinge Gowda $\mathrm{KP}^{*}{ }^{1}$ and Vrushabendra Swamy BM ${ }^{2}$ \\ ${ }^{1}$.Research Scholar, JJT University, Rajasthan, India. \\ 2. Professor and Director, Gautham College of Pharmacy, Bangalore, Karnataka, India.
}

\begin{abstract}
The histopathological changes and nephroprotective effect of aqueous stem bark extract of Ficus racemesa (ARF) in Albino wistar rats were studied. Rats were divided into four groups. Vehicle was administered to the group I (control). Nephrotoxicity was induced in the rats of group II by administering gentamicin $(80 \mathrm{mg} / \mathrm{kg}$, i.p.) for 8 days. The ARF (200 and $400 \mathrm{mg} /$ k.g.p.o) was administered to the rats of group II and IV for 11 days together with gentamicin (8days). Kidney function was assessed by measuring urine urea and creatinine and serum urea and creatinine. Kidney superoxide dismutase, lipid peroxidation, catalase and reduced glutathione were also measured in control and treated groups. Histopathological examinations were conducted to confirm the nephroprotective effect. The sign of nephrotoxicity in rats was significantly alleviated by ARF. The results of histopathological examinations also confirm the nephroprotective effect of ARF.
\end{abstract}

Keywords: Gentamicin, Ficus racemosa, creatinine, super oxide dismutase.

Introduction: Nephrotoxicity is one of the most important side effects and therapeutic limitations of aminoglycoside antibiotics, especially gentamicin. Despite rigorous monitoring, nephrotoxicity appears in $10-25 \%$ of therapeutic courses. Gentamicin mainly causes tubular toxicity, both lethal and sub-lethal alterations in tubular cells handicap reabsorption and, in severe cases, may lead to significant tubular abstruction. ${ }^{1}$ Tubular cytotoxicity is the consequence of many interconnected actions, triggered by drug accumulation in epithelial cells. Accumulation results from the presence of the endocytic receptor complex formed by megalin and cubulin, which transports proteins and organic cations inside the cells. Gentamicin the accesses and accumulates in the endosomal compartment, the Golgi and endoplasmic reticulum (ER), causes ER stress, and unleashes the unfolded protein response. An excessive concentration of the drug over an undetermined threshold destabilizes intracellular membranes and the drug redistributes throughout the cytosol. It then acts on mitochondria to unleash the intrinsic pathway of apoptosis ${ }^{2}$ Ficus racemosa Linn (Moraceae) is a popular medicinal plant in India, which has long been used in ayurveda, the ancient system of Indian medicine for various diseases/disorders including diabetes, liver disorders, diarrhoea, inflammatory conditions, and hemorrhoids, respiratory and urinary diseases. As a part of this concept survey of locally available medicinal plants was undertaken. It was observed that the plant Ficus racemosa Linn is grown widely and abundantly. In addition, a native practioner has claimed that this plant is very useful nephroprotective agent. The stem bark and fruits are used in India for the treatment of various diseases. Methanol extracts of Ficus racemosa contained relatively higher levels of total phenolics than the other extract ${ }^{3}$. However, systemic and scientific reports on the investigation of aqueous extract of stem bark extract of Ficus racemosa for its effect on renal function are scarce. In this study, the nephroprotective effects and histopathological changes caused by ARF on gentamicin induced nephrotoxic rats was evaluated.

\section{Materials and methods:}

Plant material; The stem barks of Ficus racemosa were collected and identified and authenticated by a qualified Botanist. The shade dried and powdered stem bark of Ficus racemosa $(1 \mathrm{~kg})$ was extracted with water in a Soxhlet apparatus $\left(70^{\circ} \mathrm{C} ; 3-\right.$ $4 \mathrm{~h}$ ). The aqueous extract was concentrated to a small volume and then evaporated to dryness. The aqueous stem bark extract of Ficus racemosa (ARF) was kept in air tight container and used for the present study.

Animals- Adult male albino wistar rats (150-200g) were used for the present study. The animal care and experimental protocols will be made in accordance with CPCSEA/ IAEC.

Selection of animals- After acclimatization the rats were randomly divided into four groups (6 rats/ group). Nephrotoxicity in rats (group II) was induced with the administration of gentamicin $(80 \mathrm{mg} / \mathrm{kg}$ i.p.) for 8 days. The extracts were administered (group III and IV) by orally 3 day before the administration of gentamicin and continued for another 8 days along with gentamicin. Normal control group (group I) was not administered with either extract or gentamicin. The bark extracts were administered orally and gentamicin was administered intraperitoneally. 
Collection of blood - After $24 \mathrm{~h}$ of the last administration, the rats were anesthetized with ketamine $(60 \mathrm{mg} / \mathrm{kg})$ and xylazine $(5 \mathrm{mg} / \mathrm{kg})$ given intraperitoneally and blood samples were collected by retro orbital sinus puncture. The blood was allowed to clot at $37^{\circ} \mathrm{C}$ for $40 \mathrm{~min}$ and the clot was separated. The separated serum was transferred into centrifuge tube. The serum was centrifuged at $3000 \mathrm{RPM}$ for $10 \mathrm{~min}$. The clear serum was stored refrigerator. The serum is used for the estimation of serum creatinine, and urea using semi automatic analyzer and Erba diagnostic kit. ${ }^{4}$.

Urine collection and analysis- On the last day of treatment the rats were housed in individual metabolic cages. On the day 9, urine was collected with the help of metabolic cages and the urine samples were subjected for the estimation of urinary functional parameters like glucose, potassium, creatinine and urea.

Assesement invivo antioxidant activity- After sacrificing the rats, the kidneys were quickly removed and weighed and perfused immediately with ice-cold normal saline and homogenized in chilled potassium chloride $(1.17 \% \mathrm{w} / \mathrm{v})$ using a homogenizer. The homogenate was filtered and then centrifuged at 10,000 rpm for $20 \mathrm{~min} 4^{\circ} \mathrm{C}$. The supernatant so obtained was used for the estimation of thiobarbituric acid reactive substances (TBARS) ${ }^{6}$, super oxide dismutase (SOD) ${ }^{7}$, catalase $(\mathrm{CAT})^{8}$, reduced glutathione $(\mathrm{GSH})^{9}$.

Histopathological examination: Kidneys from all the four groups were fixed in $10 \%$ neutral buffered formalin and processed to paraffin wax. The kidneys were sectioned longitudinally in two halves and were kept in $10 \%$ neutral formalin solution. Both kidneys were processed and embedded in paraffin wax and sections were taken using a microtome. The sections were stained with hematoxylin and eosin and were observed under a light microscope.

Results- There is insignificant decrease in the weights of the kidneys of the rats treated with ARF (200 and 400mg/kg) when compared to the group II rats. The urine glucose levels of the kidneys of the group II has shown significant increase when compared to the control rats. The significant reduction of the urine glucose levels was observed in the ARF (200 and $400 \mathrm{mg} / \mathrm{kg}$ ) treated rats when compared to the gentamicin treated (group II). There is no significant changes in the levels of sodium and potassium ions in the normal and treated rats. The significant decrease in the urine volume was noticed in rats treated with gentamicin (group II) when compared to the control rats. There is insignificant decrease in the urine volume levels in the ARF treated rats when compared to the gentamicin alone treated rats. There is significant increase $(p<0.05)$ in the urinary urea, urinary creatinine, serum urea and serum creatinine in rats (group II) treated with gentamicin $(80 \mathrm{mg} / \mathrm{kg})$ for 8 days, when compared to the vehicle treated control rats (group I). The significant $(p<0.05)$ decrease in the urinary urea, urinary creatinine, serum urea and serum creatinine in rats treated with ARF (200 and 400mg/kg -11 days) and gentamicin (80 mg/kg-for 8days) group III and IV respectively was noticed when compared with rats treated with gentamicin $(80 \mathrm{mg} / \mathrm{kg}$ for 8days)-group II suggesting the nephroprotection. The gentamicin control group rats also showed a significant decrease in catalase, SOD and glutathione levels in the kidney when compared to the normal control rats (groupI). The rats treated with gentamicin and ARF $(200$ and $400 \mathrm{mg} / \mathrm{kg}$ ) has shown dose dependent significant increase $(\mathrm{p}<0.05)$ in the kidney tissue as compared to the gentamicin treated group II. The gentamicin alone administered rats has shown significant increase in the lipid peroxide- an end product of lipid peroxidation, when compared to the control rats (group I). The results of the histopathological examination have shown the development of tubular dilatation, denudation, necrosis, and cast in tubules in rats administered with gentamicin $(80 \mathrm{mg} / \mathrm{kg}$ for 8 days) when compared to the normal control rats. The rats treated with gentamicin and ARF (200 and 400mg/kg) have not shown these histopathological changes when compared to the gentamicin treated rats (group II) confirming the nephroprotection.(fig No- 1 to 6 )

Discussion- The results of the present study gives the experimental evidence for ARF nephroprotective effect against gentamicin induced nephrotoxicity in rats. Ficus racemosa plants are found throughout the world as moderate woody plants or trees. It has a vast traditional role in indigenious system of medicine like ayurveda, siddha, unani and hooeopathy. The qualitative phytochemical screening showed that the whole plant is a rich source of glycosides, phenols \& flavonoids. The findings showed stem portion possesses higher percentage of phenols $(8.03 \%)$ as compared to leaf $(3.64 \%)$ and root (5.01\%).Tannins were estimated by Folin-Denis method. Results showed stem possesses higher percentage (5.94\%) of tannin as compared to leaf $(2.06 \%)$ and root $(4.65 \%) .{ }^{10}$ Administrations of gentamicin $(80 \mathrm{mg} / \mathrm{kgi} . \mathrm{p}$.) for 8 days reported to causes nephrotoxicity. The rats administered with gentamicin have shown significant increased levels of serum urea, serum creatinine, urinary urea, urinary creatinine, kidney peroxide levels. The kidney tissues of these rats also showed the significant decrease in the SOD, catalase and GSH levels. The creatinine is easily filtered by the renal glomerulus. Tubular reabsorption does not occur. The increased serum creatinine level is produced by kidney damage, which leads to a decreasing GFR and serum creatinine filtration. The increase in the serum creatinine levels in the GN treated group is due to decreased GFR caused by the gentamicin. The serum urea accumulates in renal diseases, because the rate of serum urea production 
exceeds the rate of clearance. ${ }^{11}$ In conclusion, aqueous stem bark extracts of Ficus racemosa contain phytoconstituentsflavonoids, tannins which could enhance renal mitochondrial antioxidant system, thereby protecting against gentamicin toxicity. Although, the active principles were not isolated and their possible mechanism of actions was not investigated in this study, these could constitute areas of future studies.

Table-I: Table showing the effects on weight of kidney, urine glucose, urine potassium and urine volume in normal and gentamicin and ARF administered rats.

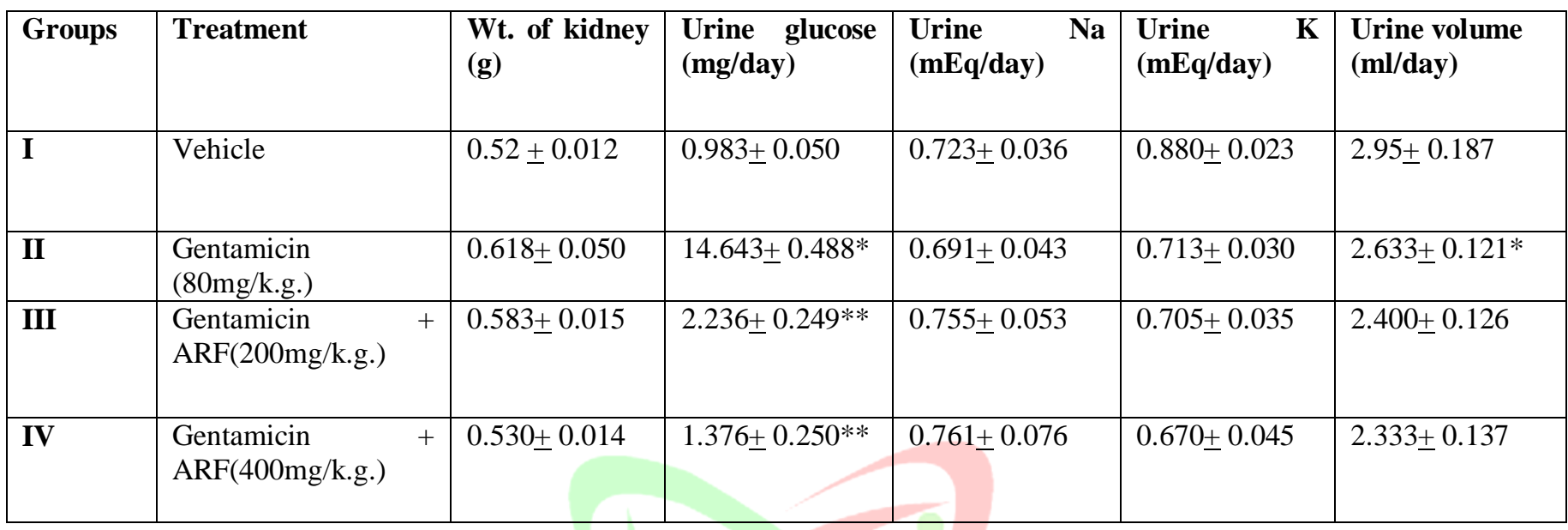

Results of group II rats were compared with group I. The results of group III, and IV rats were compared with group II rats. Values are shown in mean \pm SEM. Data is analyzed by one way ANOVA followed by Tukey's test. Values of $\mathrm{p}<0.05$ were considered as significant.

Table-II: Table showing the effects on urine urea, urine creatinine, serum urea, serum creatinine, in normal, gentamicin, and ARF treated rats.

\begin{tabular}{|l|l|l|l|l|l|}
\hline Gs & Treatment & $\begin{array}{l}\text { Urine urea } \\
(\mathbf{m g} / \mathbf{d L})\end{array}$ & $\begin{array}{l}\text { Urine creatinine } \\
(\mathbf{m g} / \mathbf{d L})\end{array}$ & $\begin{array}{l}\text { Serum urea } \\
(\mathbf{m g} / \mathbf{d L})\end{array}$ & $\begin{array}{l}\text { Serum creatinine } \\
(\mathbf{m g} / \mathbf{d L})\end{array}$ \\
\hline I & Control (vehicle) & $35.055 \pm 0.055$ & $93.50 \pm 3.210$ & $42.50 \pm 2.590$ & $0.69 \pm 0.010$ \\
\hline II & Gentamicin+ vehicle & $57.59 \pm 2.370^{*}$ & $244.170 \pm 4.40^{*}$ & $94.170 \pm 3.71^{*}$ & $1.023 \pm 0.086^{*}$ \\
\hline III & $\begin{array}{l}\text { Gentamicin+ } \\
\text { ARF(200mg/kg) }\end{array}$ & $38.293 \pm 0503 * *$ & $122.170 \pm 8.010^{* *}$ & $49.500 \pm 2.170^{* *}$ & $0.786 \pm 0.043^{* *}$ \\
\hline IV & $\begin{array}{l}\text { Gentamicin+ } \\
\text { ARF(400mg/kg) }\end{array}$ & $36.928 \pm 0.595^{* *}$ & $99.00 \pm 3.520 * *$ & $47.50 \pm 1.520^{* *}$ & $0.740 \pm 0.031^{* *}$ \\
\hline
\end{tabular}

Results of group II were compared with group I. The results of group III, and IV were compared with group II. The values are shown in mean \pm SEM. Data was analyzed by one way ANOVA followed by Tukey’s test. Values of $p<0.05$ were considered as significant. 
Table: III-Table showing the effects on lipid peroxidation, SOD, catalase and GSH in normal, gentamicin, and ARF treated rats.

\begin{tabular}{|l|l|l|l|l|l|}
\hline Gs & Treatment & $\begin{array}{l}\text { Lipid peroxidation } \\
\mathbf{m M / 1 0 0 g} \text { tissue }\end{array}$ & $\begin{array}{l}\text { SOD (Units /mg of } \\
\text { protein) }\end{array}$ & $\begin{array}{l}\text { Catalase (U/mg } \\
\text { protein) }\end{array}$ & $\begin{array}{l}\text { GSH } \\
\text { protein }\end{array}$ \\
\hline I & Control (vehicle) & $27.705 \pm 0.795$ & $3.493 \pm 0.335$ & $19.773 \pm 0.596$ & $21.338 \pm 1.018$ \\
\hline II & Gentamicin & $36.590 \pm 0.913^{*}$ & $1.988 \pm 0.141^{*}$ & $10.300 \pm 0.848^{*}$ & $10.170 \pm 0.372^{*}$ \\
\hline III & $\begin{array}{l}\text { Gentamicin+ } \\
\text { ARF(200mg/kg) }\end{array}$ & $29.438 \pm 1.647^{* *}$ & $4.891 \pm 0.331^{* *}$ & $13.580 \pm 0.731^{* *}$ & $18.563 \pm 0.570^{* *}$ \\
\hline IV & $\begin{array}{l}\text { Gentamicin } \\
\text { ARF(400mg/kg) }\end{array}$ & $28.698 \pm 1.796^{* *}$ & $4.725 \pm 0.656^{* *}$ & $13.528 \pm 0.381^{* *}$ & $18.853 \pm 0.391^{* *}$ \\
\hline
\end{tabular}

Results of group II were compared with group I. The results of group III, and IV were compared with group II. The values are shown in mean \pm SEM. Data was analyzed by one way ANOVA followed by Tukey's test. Values of $p<0.05$ were considered as significant.

Table:IV- Table showing the effects on histopathological changes in the kidneys of normal, gentamicin and ARF treated rat.

\begin{tabular}{|l|l|l|l|l|l|l|l|}
\hline Group & Treatment & $\begin{array}{l}\text { Glomerular } \\
\text { congestion }\end{array}$ & $\begin{array}{l}\text { Glomerular } \\
\text { hemorrhage }\end{array}$ & $\begin{array}{l}\text { Epithelial } \\
\text { proliferation }\end{array}$ & $\begin{array}{l}\text { Tubular } \\
\text { atrophy }\end{array}$ & $\begin{array}{l}\text { Tubular } \\
\text { dilatation }\end{array}$ & $\begin{array}{l}\text { Denudation } \\
\text { and } \\
\text { necrosis }\end{array}$ \\
\hline I & Control (vehicle) & Nil & Nil & Nil & Absent & Absent & Absent \\
\hline II & Gentamicin & Nil & Nil & Nil & Absent & Present & Present \\
\hline III & $\begin{array}{l}\text { Gentamicin+ } \\
\text { ARF(200mg/kg) }\end{array}$ & Nil & Nil & Nil & Absent & Absent & Absent \\
\hline IV & $\begin{array}{l}\text { Gentamicint } \\
\text { ARF }(400 \mathrm{mg} / \mathrm{kg})\end{array}$ & Nil & Nil & Nil & Absent & Absent & Absent \\
\hline
\end{tabular}

Table:V- Table showing the effects on histopathological changes in the kidneys of normal, gentamicin and ARF treated rat.

\begin{tabular}{|l|l|l|l|l|l|l|}
\hline Group & Treatment & Cast in tubules & $\begin{array}{l}\text { Hemosiderin in } \\
\text { tubules }\end{array}$ & $\begin{array}{l}\text { Epithelial } \\
\text { regeneration }\end{array}$ & $\begin{array}{l}\text { Interstitial } \\
\text { inflammation }\end{array}$ & $\begin{array}{l}\text { Blood } \\
\text { vessels }\end{array}$ \\
\hline I & $\begin{array}{l}\text { Control } \\
\text { (vehicle) }\end{array}$ & Absent & Absent & Absent & Focal & Normal \\
\hline II & Gentamicin & Present & Absent & Absent & Focal & Normal \\
\hline III & $\begin{array}{l}\text { Gentamicin+ } \\
\text { ARF(200mg/k } \\
\text { g) }\end{array}$ & Absent & Absent & Absent & Focal & Normal \\
\hline IV & $\begin{array}{l}\text { Gentamicin+ } \\
\text { ARF(400mg/k } \\
\text { g) }\end{array}$ & Absent & Absent & Absent & Focal & Normal \\
\hline
\end{tabular}




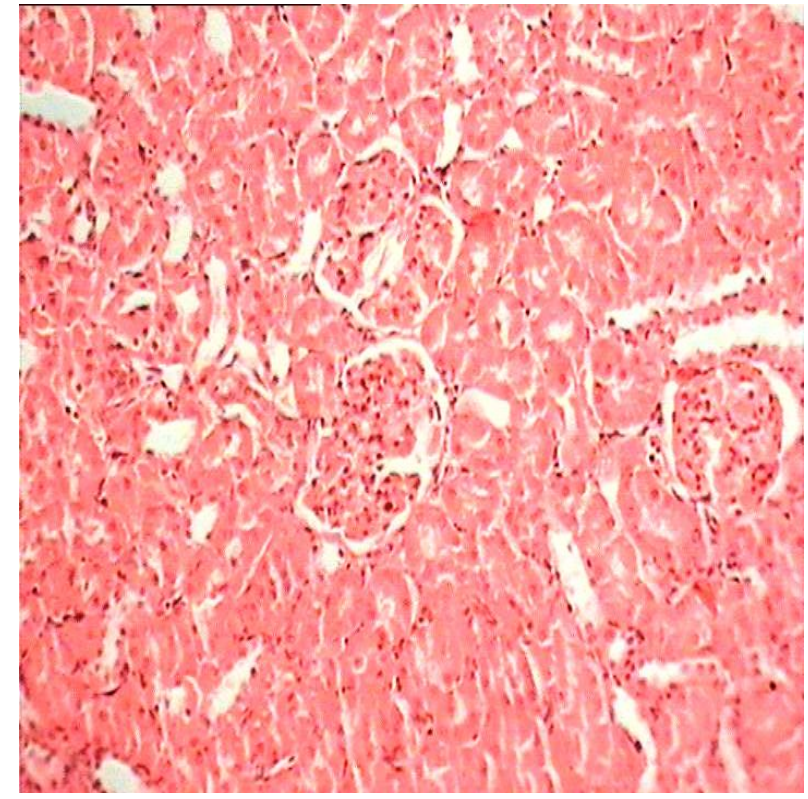

Fig- 1-Control- Group I -Normal

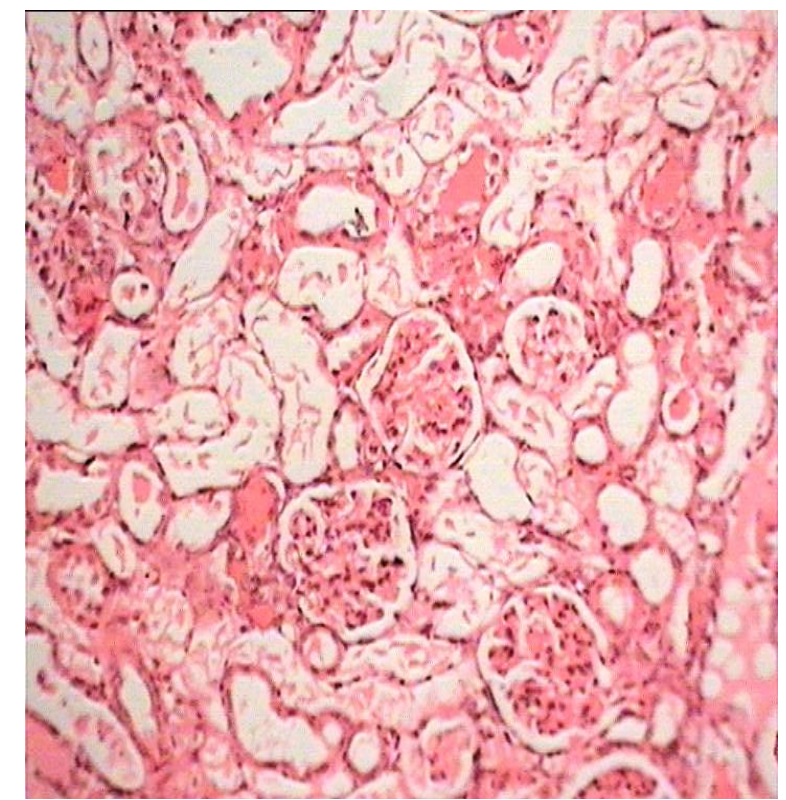

Fig 2- Group II Gentamicin treated rat

(Fig-2 Showing the presence of tubular dilatation, denudation, necrosis, cast in tubules.)

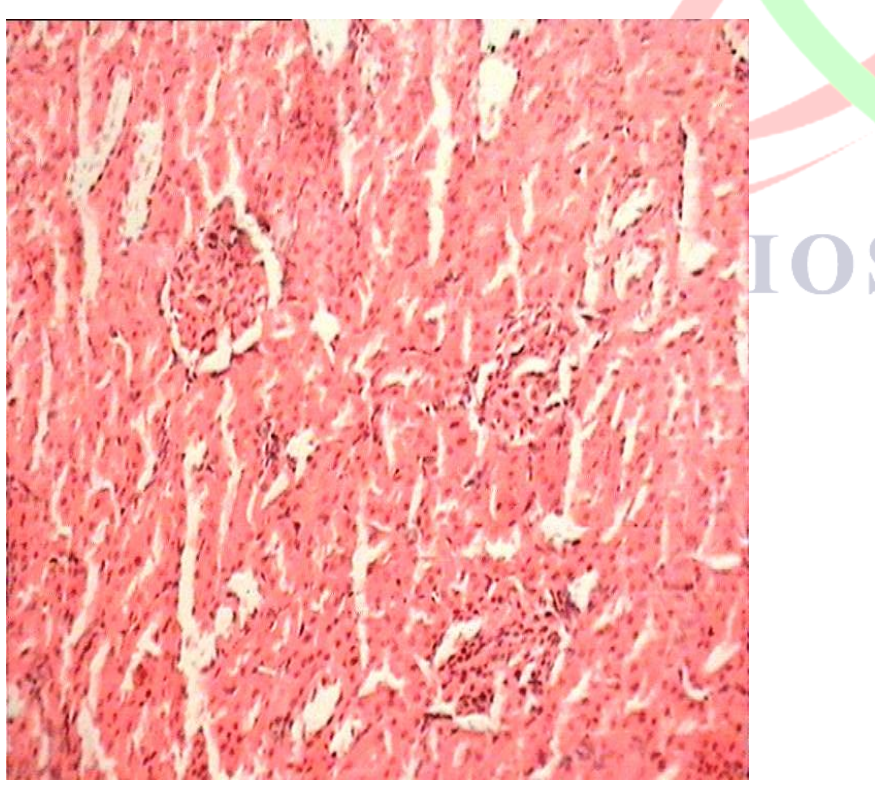

Fig- 3-Group III GM+ ARF (200mg/kg)

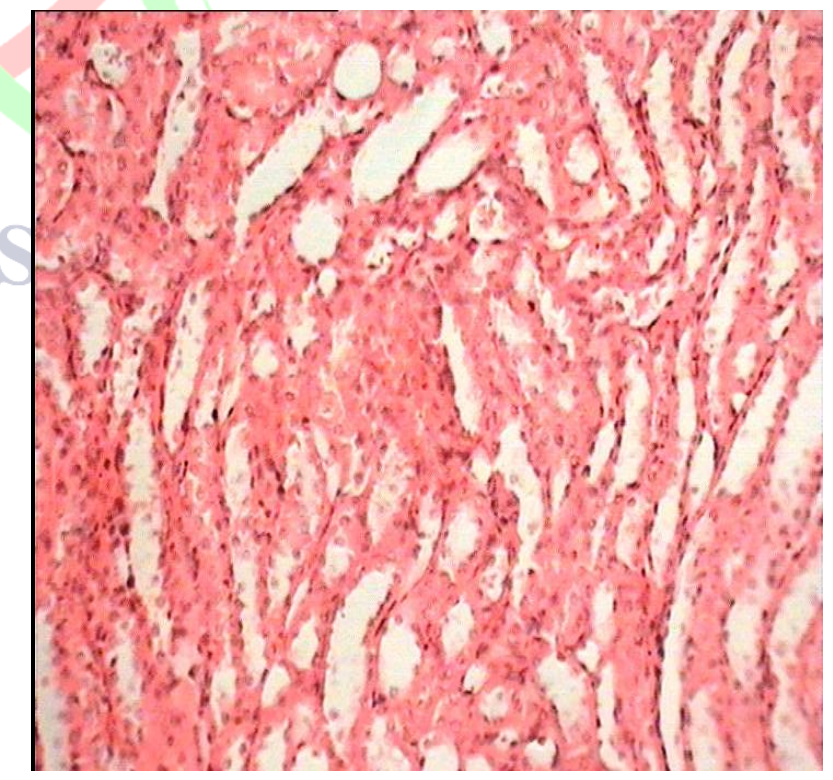

Fig- 4- Group IV+ ARF (400mg/kg)

(Fig-3-4 Showing the absence of tubular dilatation, denudation, necrosis, cast in tubules.) 


\section{References-}

1. Jose M Lopez-Novoa, Yaremi Quiros, Laura Vicente, Ana I Morales, Francisco J Lopez-Hernandez. New insights into mechanism of aminoglycoside nephrotoxicity: an integrative point of view. Kidney International. $2011 ; 79,33-45$.

2. Yaremi Quiros,Laura Vicente-Vicente, Ana I.Morales, Jose M Lo pez-Novoa and Francisco J Lo pezHerna'ndez. An intergrative overview on the mechanism underlying the renal tubular cytotoxicity of gentamicin. Technological Sciences.2011; 119(2),245-56.

3. Baby Joseph, JustinR. Phytopharmacological properties of Ficcus racemosa Linn an overview. International Journal of Pharmaceutical Sciences Review and Research.2010;3(2),134-8.

4. Nigam. Lab manual in Biochemistry, Immunology and Biotechnology. Tata McGraw-Hill Education, 2007.

5. Arvind $\mathrm{S}$ Yadav, Sharda $\mathrm{R}$ Deshmukh, Promod $\mathrm{S}$ Kamble. Comprehensive Practical and Viva in Biochemistry.Jaypee Brothers medical Publishers (P) Ltd. New Delhi, 2004;pp100-6.

6. Ohkawa H, Ohishi N, Yagi K. Assay for lipid peroxides in animal tissues by thiobarbituric acid reaction. Anal Biochem. 1979;95, 351-8.

7. Kakkar P, Das B, Viswanathan PN. A modified spectrophotometric assay os superoxide dismutase. Ind J Biochem Biophys 1984; 21, 130-2.

7. Sinha AK. Colorimetric assay of catalase. Anal Biochem. 1972; 47, 389-94.

8. Ellima GC. Tissue sulfhydril groups. Arch Biochem Biophys. 1959; 82, $70-7$.

9. Baby Joseph and Justin RS. Phytopharmacological and phytochemical properties of three Ficus species-an overview.International Journal of Pharma and Bio Sciences. 2010; 1(4), 246-53.

10. Arunachalam A, Venkatesan, Senthilraj, Vijaykumar G, Karthikeyan and Ashutoshkumar. Phytopharmacognostical properties of Ficus racemosa Linn. International Journal of Comprehensive Pharmacy. $2010 ; 5(04), 1-3$.

11. Kishor K and Singh M. effect of becosides, an alcoholic extract of Bacopa monnieri amnesia in mice. Indian J of Exper Biol. 2005; 43, 640-5. 